\title{
Living with an Active Volcano: \\ Informal and Community Learning for Preparedness in South of Japan
}

\author{
Kaori Kitagawa
}

\begin{abstract}
In a disaster-prone country like Japan, learning how to live with disaster [kyozon] has been crucial. Particularly since the Great East Japan Earthquake and Tsunami of 2011, disaster preparedness has been a primary concern of the government. Drawing on Paton's (The phoenix of natural disasters: community resilience. Nova Science Publishers, New York, pp. 13-31, 2008) Community Engagement Theory, which endorses an integrated model that combines risk management with community development, this study discusses the case of Sakurajima Volcano (SV) situated in the south of Japan, with a focus on how the lessons learnt from previous eruption experiences have informed present-day preparedness activities. The study adapts Community Engagement Theory's quantitative framework to a qualitative analysis to consider the preparedness teaching and learning of a population living with the everyday threat of volcanic hazards in the case of SV. The study argues that two particular local lores-'do not rely on authorities' and 'be frightened effectively' - have been the underlying principles in volcanic preparedness in the region. The study also argues that the notion of "kyojo [collaborative partnerships]' has been central to the planning and implementation of preparedness programmes, such as the Sakurajima Taisho Eruption Centenary Project, which offered a wide range of informal teaching and learning opportunities. Applying the framework of Community Engagement Theory, the paper suggests that at the individual level, the principles of 'do not rely on authorities' and 'be frightened effectively' form the basis for positive 'outcome expectancy'. At the community level, 'kyojo' is the notion which encompasses both of the community factors- 'community participation' and 'collective efficacy'. At the societal level, 'kyojo'
\end{abstract}

K. Kitagawa $(\bowtie)$

Cass School of Education and Communities,

University of East London, E15 4LZ London, UK

e-mail: k.kitagawa@uel.ac.uk 
contributes to the building of 'empowerment' and 'trust' between citizens and authorities. The paper concludes by proposing that the SV case can be considered as an example of 'the integrated model'.

\section{Introduction}

Japan is located in the Circum-Pacific Mobile Belt where seismic and volcanic activities occur constantly (Cabinet Office 2011). The teaching and learning of disaster preparedness has been a primary concern of the government, particularly since the Great East Japan Earthquake and Tsunami of 2011 (Kitagawa 2014; The Expert Committee $^{1}$ 2012). Where natural disasters are not exceptional (Preston et al. 2014), learning how to live with disaster [kyozon] has been crucial. This paper examines preparedness for Sakurajima Volcano, which is an active volcano in Kagoshima City, Kagoshima Prefecture in Japan. In Japanese, 'Sakurajima' refers to both the volcano and the island. ${ }^{2}$ In this paper, Sakurajima as a volcano is referred to as 'Sakurajima Volcano (SV)', and Sakurajima as an island is called 'Sakurajima'. Focusing on how lessons have been learned from previous eruption experiences, the study aims to contribute to the development of a preparedness model of 'living with an active volcano'.

In Japan, volcanic preparedness was systematised in a government-led initiative (1974-2008) (Ishihara 2012), which introduced the volcanic warning system and implemented mitigation plans, hazard maps and evacuation plans for major active volcanoes. However, prevention, response and recovery measures for volcanic disaster have not been as advanced as those for

\footnotetext{
${ }^{1}$ The Expert Committee to Discuss Disaster Education and Management Considering the Lessons Learnt From the Great East Japan Earthquake [Higashinihon daishinsai o uketa bosaikyoiku/bosaikanri ni kansuru yushikisha kaigi].

${ }^{2} 90 \%$ of Sakurajima Island is occupied by the volcano. Sakurajima has been referred to as an island rather than a peninsula although the island was connected to the mainland by a lava flow in 1914 .
}

earthquakes or floods (Takahashi 2007). This was unfortunately demonstrated by the recent disaster at Ontake Volcano in central Japan, which has become the worst volcanic disaster in Japan in the past 90 years (BBC 2014), since the 1914 eruption of SV. ${ }^{3}$ Prior to the eruption, there had been debate about whether to raise the warning level which was Level $1^{4}$ at the time. The incident reconfirmed the complex nature of volcanic preparedness.

This paper discusses the development of the volcanic preparedness in the Kagoshima region (Fig. 1). The purpose is twofold: first, to examine how the lessons learnt from the Taisho Eruption ${ }^{5}$ of 1914 have informed present-day preparedness activities; and second, to explore whether the SV case can be considered as 'an integrated model' endorsed by Paton's Community Engagement Theory (CET). The paper first argues that two particular local lores - 'do not rely on authorities [riron ni shinraisezu]' and 'be frightened effectively [seito ni kowagaru] ${ }^{6}$ - have taught the local population the underlying principles of volcanic preparedness - the development of

\footnotetext{
${ }^{3}$ Ontake Volcano erupted on 27 September 2014, killing 51 people (as of 31 October 2014). The victims who were mostly hikers were said to have covered by dense ash fall and inhaled poisonous fumes or hit by ash deposits thrown out from the crater.

${ }^{4}$ The current official volcanic warnings set by the Japan Meteorological Agency are: Level 1 Normal; Level 2 Do not approach the crater; Level 3 Do not approach the volcano; Level 4 Prepare to evacuate; Level 5 Evacuate. ${ }^{5}$ Japan uses its own name of an era which refers to the Emperor at the time. Taisho Era was 1912-1926, the reign of Taisho Emperor, Yoshihito. Showa Era was 19261989, the reign of Showa Emperor, Hirohito. The current era is Heisei Era, the reign of Heisei Emperor, Akihito. The eruption of 1914 occurred during Taisho Era, and therefore it has been referred to as 'Taisho Eruption'.

${ }^{6}$ The former is part of the inscription on the Sakurajima Taisho Eruption Monument, and the latter is the words from an intellectual.
} 
Fig. 1 Map of Kagoshima

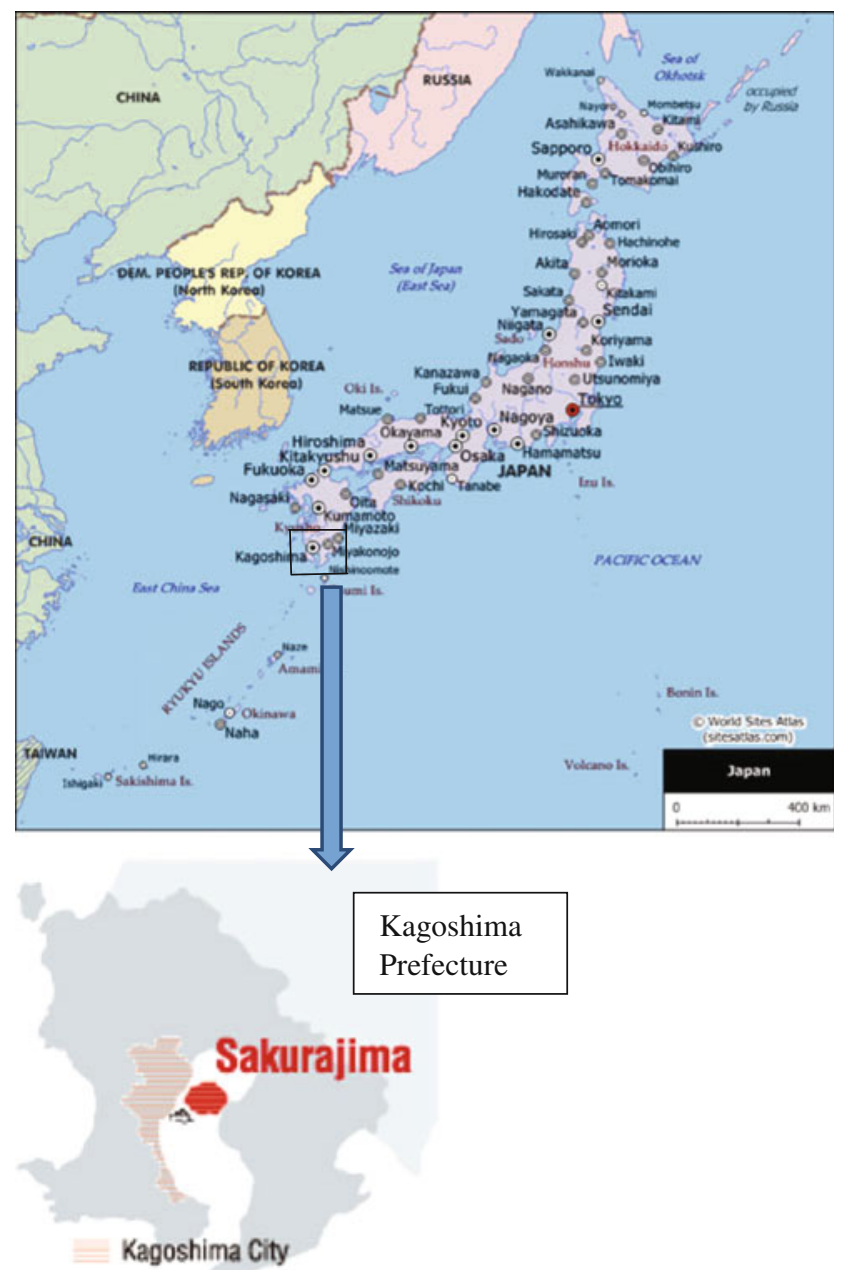

agency and the control of emotion. The paper also looks at the implementation of the above two principles through informal ${ }^{7}$ teaching and learning programmes. The paper argues that those programmes are based on 'kyojo' laborative partnerships - which has become the key policy term in disaster preparedness in Japan particularly since 2011 .

\footnotetext{
${ }^{7}$ Here, 'informal' teaching and learning refers to a form of teaching and learning outside of formal schooling.

${ }^{8}$ 'Kyojo' is part of the four forms of aid: kojo, jijo, gojo and kyojo. The common word 'jo' at the end means 'aid'. 'Kojo' is aid provided by governments, both central and local, and 'jijo' is self-help. 'Gojo and 'kyojo' refer to mutual help, however, the difference lies in that the former happens within the people you are familiar with, whereas the latter has a philanthropic nature.
}

In parallel, the paper discusses the qualitative findings, applying the individual/community/ societal framework of CET. The argument of the theory is that 'an integrated model' that combines risk management and community development is an effective and sustainable approach to enhance community resilience to adversity (Paton et al. 2011; Paton 2008; Paton and Johnston 2006). Unlike Paton et al's (2013) and Paton and Jang's (2013) studies, this paper is not measuring the factors that contribute to people's intention to prepare for disaster, rather the variables of the theory-'outcome expectancy', 'community participation', 'collective efficacy', 'empowerment', 'trust' - are employed to consider the preparedness teaching and learning of a 
population living with the everyday threat of volcanic hazards in the case of SV.

The paper is structured in the following way. The first section of the paper is about methodological and theoretical considerations of this study. This is followed by a description of the major volcanic activities of SV. The paper then analyses the population response to the Taisho Eruption, lessons learned from it and present-day communication about volcanic conditions in the Kagoshima region. In doing so, the paper connects the findings from the SV case to the key concepts of CET. The challenges that the government and the population face in living with the active volcano are also discussed.

\section{Methodological and Theoretical Considerations}

This case study particularly focused on two aspects of the disaster cycle: how population response informs disaster prevention and reduction. More concretely, the following six questions were pursued:

1. What lessons were learnt from the Taisho Eruption of 1914 ?

2. Why did false rumours circulate? What did the phrase 'do not rely on authorities' aim to convey?

3. How is the phrase 'learning to be frightened effectively' understood? What measures have been undertaken to teach the principle?

4. What forms of volcanic preparedness particularly outside of formal schooling are currently in place?

5. SV has been active again since 2006 , and the Warning Level has remained at 3 since 2012. The local population are used to regular volcanic hazards, and Level 3 has become a norm to them. Under such circumstances, how do they learn/have they learned 'to be frightened effectively'?

6. What are the examples of kyojo activities for the teaching and learning of 'do not rely on authorities' and 'be frightened effectively'?
Data collection and analysis were arranged to respond to the above questions in the following way. First, the study made use of the rich information available in the documentation of the Taisho Eruption undertaken as part of the Sakurajima Taisho Eruption Centenary Project (Centenary Project). ${ }^{9}$ Empirical fieldwork was then organised in order to triangulate the information obtained from the documentary analysis. Sakurajima itself and two museums (the Sakurajima Visitor Center and the Prefectural Museum of Kagoshima) were visited to familiarise myself with the volcanology of SV and to obtain the official archival record of the eruptions, responses and recovery. Semi-structured interviews were conducted with three groups of experts: regional policy makers, ${ }^{10}$ academics ${ }^{11}$ and a curator/researcher of an archival museum. ${ }^{12}$ In addition, online resources such as newspaper articles were used to fill any gaps. Thus, the data were analysed according to the six questions, while being collected at each step of the data collection-documentary analysis, archival research and expert interviews.

CET is based on the perspective that risk management and community development as complementary, and such an integrated model of preparedness permits a resilient community. ${ }^{13}$ Paton's (2008, p 3) approach is that 'people's understanding of, and response to, risk is determined not only by scientific information about risk, but also by the manner in which this information interacts with psychological, social,

\footnotetext{
${ }^{9}$ The Centenary Project was implemented in 2013-14 funded by the prefectural and municipal governments of Kagoshima. The detail of the Centenary Project is introduced in the later section.

${ }^{10}$ From the Risk Management and Disaster Prevention Unit from the Kagoshima City authority. Interviewed on 22 July 2014.

${ }^{11}$ From the Regional Disaster Reduction Education and Research Center at Kagoshima University. Interviewed on 23 July 2014.

${ }^{12}$ From the Prefectural Museum of Kagoshima. Interviewed on 23 July 2014.

${ }^{13}$ In Japan, for example, Shiroshita's (2010) 'collaborative education [kyoiku]' is a similar notion, which emphasises collaborative and democratic partnerships, and ownership by the members of the community.
} 
cultural, institutional and political processes to influence outcome....these factors must be understood and accommodated in risk communication strategies'. The theory suggests that interpretive process at the individual level (outcome expectancy) interacts with communities (community participation, collective efficacy) and societal relationship (empowerment, trust) factors to influence preparedness (Paton 2008). Quantitative methods are usually applied in finding out the interactions between the preparedness variables. As a qualitative study, this paper does not intend to measure those interactions, but to explore how the findings of the case of SV could be interpreted, borrowing those concepts.

Five key concepts of the theory are briefly explained here. 'Outcome expectancy' at the individual level is about a person's belief as to whether her/his actions can effectively mitigate or reduce the problem (Paton et al. 2013, p. 21). At the community level, 'community participation' refers to community members' ability to collaborate to make decisions on effective responses for possible hazards and mitigation strategies. 'Collective efficacy' is community members' ability to assess their capabilities and create plans. The societal-level 'empowerment' and 'trust' variables refer to the relationship between citizens and authorities. When people believe their relationship with authorities is fair, empowering and trustworthy, people are more willing to get involved and take responsibility for their own safety (Paton et al. 2013, p. 22).

The paper now moves on to consider the case of SV with reference to this framework.

\section{Sakurajima Volcano's Activities}

\subsection{Overview of Volcanic Activities}

SV emerged about 26,000 years ago at the south end of Aira Caldera. The volcano currently has three peaks - Kitadake (north mountain), Nakadake (middle mountain) and Minamidake (south mountain) which has been most active (Japan Meteorological Agency 2014). In its recorded history, SV has had 17 major eruptions, the ones in 746, 1472, 1779 and 1914 being the largest four. Except the 19 years after the Taisho Eruption of 1914, SV has continuously been active during the past 100 years. In 1946, the lava flow exploded near the peak of Minamidake, created the Showa Crater $^{14}$ and buried two villages. The Minamidake crater has been active since $1955,{ }^{15}$ and between 1972 and the early 1990s, eruptions were frequent ${ }^{16}$ (Centenary Committee ${ }^{17} 2014$, p 156; Ishikawa cited in Kagoshima University ${ }^{18}$ 2014 , p. 39). SV was less active until 2006, eruptions have become more frequent since 2009, and in 2012, the Meteorological Agency announced the volcanic alert Level 3-'do not approach the volcano'-which has remained unchanged since. ${ }^{19}$

Research has confirmed that 90 percent of the magma which erupted in 1914 has already been re-accumulated in the underground of Aira Caldera which is said to be the main magma reservoir of SV. Three concrete scenarios have been proposed: (1) the re-aggravation of the Minamidake crater; (2) the aggravation of the Showa Crater followed by large lava flows; (3) flank eruptions of the scale of the Taisho Eruption from both mountainsides (Centenary Committee 2014, p. 142). Science and technology have advanced understanding of the volcano, and preparedness education for the above scenarios are underway. The circumstances at the time of the Taisho Eruption, however, were very different.

\footnotetext{
${ }^{14}$ As explained above, 'Showa' refers to the era of Showa. Some refer to this eruption as 'the Showa Eruption'.

${ }^{15}$ Its summit erupted causing a $5000 \mathrm{~m}$ volcanic fume and a high volume of ash deposits which killed one hiker and injured a few others.

${ }^{16}$ During this period, secondary damage was a concern because rain turned the accumulated ash fall into sediment flows threatening the life of the people of the island.

${ }^{17}$ The Planning Committee of the Sakurajima Taisho Eruption Centenary Project.

${ }^{18}$ The Department of Domestic Science Education, Faculty of Education, Kagoshima University.

${ }^{19}$ In August 2013, there was an explosive eruption, resulting in a 5,000-metre volcanic fume and a large quantity of ash fall which reached the city of Kagoshima. The number of recorded eruptions per year in the past five years has been $896,996,885,835$ and for 2014 , as of 13 August, 209 had already been recorded.
} 


\subsection{Taisho Eruption: The Largest in the 20th Century in Japan}

At 10:05 on 12 January in 1914, a flank eruption occurred on the west mountainside, and $15 \mathrm{~min}$ later, a larger flank eruption occurred on the east mountainside of SV. ${ }^{20}$ The volcanic fume rose more than $8000 \mathrm{~m}$, and the ash fall reached as far as the Kamchatka in Russia. Eight hours after the eruption at 18:30, a Magnitude 7.1 earthquake hit the city of Kagoshima. At 20:14, pyroclastic flow began, which burnt whole villages on the west side of the island. From at around 21:00, the pyroclastic flow turned to lava flows, which reached the coastline by the following evening. ${ }^{21}$ The total amount of the ash fall was estimated to be two square kilometres, and that of the lava flows was three billion tons. The accumulated ash fall became sediment flows in the mountains in the region, as well as in Sakurajima (Central Disaster Council 2011, p. 38; Kagoshima University 2014, p. 41).

\subsection{Damage Brought About by the Taisho Eruption}

In 1914, Sakurajima was made up of 3400 households and 21,300 inhabitants. Given the scale of the eruption, the human damage on the island - 30 dead or missing — was considered to be small. Of the 30 , only two deaths were directly caused by volcanic ejecta. The majority were drowned trying to escape by sea $^{22}$ (Centenary Committee 2014, p. 51; Central Disaster Council 2011, p. 40). The property damage was enormous. On Sakurajima, a number of villages were swallowed completely by lava or covered

\footnotetext{
${ }^{20}$ The Taisho Eruption was part of the geodetic phenomena in the region surrounding Kagoshima Prefecture since 1913.

${ }^{21}$ The lava flow from the west mountainside continued for two months, whereas the one from the east mountainside continued for nearly a year, which connected Sakurajima and Osumi Peninsula.

${ }^{22}$ The earthquake in Kagoshima City added 29 deaths and 111 injured.
}

by ash. 62 percent of the houses were burnt down by lava and pyroclastic flows. Residents in surrounding cities also lost homes which were covered by thick ash fall. The earthquake also destroyed houses in Kagoshima City ${ }^{23}$ (Centenary Committee 2014, p. 52; Central Disaster Council 2011, p. 40). Nearly half of the population in total had to migrate from Sakurajima after the Taisho disaster (Central Disaster Council 2011, pp. 44-45).

Infrastructure failure was massive. Roads were closed and bridges were destroyed on Sakurajima. On the mainland, some railway lines were destroyed, and telecommunications were disrupted due to the collapse of stations and electrical failure. Agricultural crops in Sakurajima were significantly damaged as well ${ }^{24}$ (Centenary Committee 2014, pp. 40-45, 52; Central Disaster Council 2011, pp. 39-41; Kagoshima University 2014, p. 42). Moreover, secondary damage continued for another 10 years. The mountain, still covered by a large amount of ash fall, was attacked by torrential rains in the following months, which led to frequent sediment flows sweeping away more farms and houses. A number of floods were caused by rising river beds because of the accumulated ash fall (Centenary Committee 2014, pp. 46-50).

\section{Population Response of the Taisho Eruption}

\subsection{Delayed and Divided Responses}

Prior to the eruption, many islanders picked up the warning signs of a large-scale eruption. These included the drop in water levels in wells and continuous earth tremors. They began preparing for self-evacuation without waiting for an official instruction. Such lessons had been handed down from previous generations. However, the official

\footnotetext{
${ }^{23}$ Out of the 13,000 houses, $1.3 \%$ totally collapsed and $70 \%$ partly collapsed.

${ }^{24}$ Agriculture being the primary industry of the island, Kagoshima Prefecture had to face the economic implications of the damage in the following years.
} 
forecast from the local meteorological station stated 'no threat of a SV eruption'. In those days, there was only one old-style seismograph and no expert in volcanology or seismology was based at the station. Following the station's announcement, village authorities advised villagers there would be no need for evacuation. The response of the general public was divided. About half the islanders ignored the official view and followed their own judgement based on the aforementioned warning signs and evacuated the island before the actual eruption. The better-educated, however, followed official advice and waited until it was too late. The 30 fatalities mentioned above were made up people who followed official advice and remained on the island. The official forecast also delayed the response of the prefectural and municipal governments and the police (Centenary Committee 2014, pp. 32-34; Central Disaster Council 2011, pp. 31-42).

\subsection{Panic Followed by False Rumours}

When the Magnitude 7.1 earthquake hit Kagoshima City, the false rumour spread across the city that 'a massive tsunami and a poisonous gas attack will hit the region soon'. It is said that the rumour was created by college students whose motivation was unknown. However, the rumour contributed to a surge of panic, resulting in extreme behaviours such as people rushing to the main railway station leaving everything behind. Kagoshima City became literally empty at one point. The turmoil continued until 13 days after the eruption when a professor of seismology travelled from Tokyo and convinced the population in Kagoshima, that there was "no further threat to the city' (Centenary Committee 2014, p. 34; Central Disaster Council 2011, p. 43).

In Kagoshima, two important lessons have been emphasised since the experience of this disaster. The next section explores how those lessons can be understood in the context of CET that connects personal, community and societal factors with preparedness and resilience.

\section{Lessons Learnt: 'Do not Rely on Authorities' and 'Be Frightened Effectively'}

\section{1 'Do not Rely on Authorities' - the Development of Agency}

After the Taisho Eruption, 64 stone monuments were built within Kagoshima Prefecture. Some of these were to commemorate migration, but the majority conveyed the lessons learnt from the disaster (Suzuki 2014). One of the best-known monuments is the Sakurajima Taisho Eruption Monument built 10 years after the disaster in a village in east Sakurajima. Called 'The Monument to the Distrust of Science', part of the inscription literally says, 'citizens must not rely on theory [jumin wa riron ni shinraisezu]' (Centenary Committee 2014, p. 57; Central Disaster Council 2011, p. 42). The words refer to the story of the 30 islanders who lost their lives because they did not evacuate, following the authority's instruction and trusting the 'scientific' judgement of the meteorological station. The village mayor who had trusted the forecast regretted advising the villagers to stay on the island and felt it was his responsibility to convey the lesson to future generations. ${ }^{25}$

The meaning of the inscription requires a further explanation. What it intended to convey was not the denying of scientific theories and methods, but the importance of individuals' proactive and responsible attitude towards disaster preparedness (Centenary Committee 2014, p. 57; Central Disaster Council 2011, p. 42). The inscription promoted the development of citizens' 'agency', as an antithesis to the passive attitude of the 30 villagers who completely relied on the authority's instruction. Despite the wording of 'theory' and 'science', the underlying message was that citizens should exercise agency being proactive about and responsible for their own safety. Based on this interpretation, this

\footnotetext{
${ }^{25}$ The village mayor himself could not achieve this goal during his time, but it was succeeded to the next mayor who built the monument.
} 
study has rephrased the translation to "not to rely on "authorities".

\section{2 'Be Frightened Effectively'- the Control of Emotion}

'It is easy not to be frightened or to be too frightened of disaster, but it is difficult to be frightened effectively' (Terada cited in Centenary Committee 2014). It was Torahiko Terada, a seismologist, biologist and poet at the time of the Taisho Eruption, who left this lore. It has been considered as 'the appropriate framework for disaster preparedness' in Kagoshima Prefecture because the ability to control fear and anxiety is considered crucial in living with an active volcano. The approach taken in the region for the teaching and learning of the control of emotion is the development of two types of knowledge: the balanced knowledge about the volcano and the correct knowledge about the volcano. The former refers to both the benefits that human beings gain from the volcano and the threats that human beings may receive from the volcano. As an official from a municipal government (Interview 2014) indicated, 'people have to understand about the volcano. Without knowledge, they will be indifferent or panic. The emphasis should equally be on the understanding of the awe of nature and of the benefits humans receive from nature'. ${ }^{26}$ In terms of the correct knowledge, it refers to the validity and accuracy of the information. A researcher and curator of the prefectural museum argues (Interview 2014) that understanding the volcano should be supported by 'evidence-based information and education, which is the only effective and appropriate means'. Thus, Terada's words have been interpreted in the region that having both the balanced and the correct knowledge would enable citizens to make sound judgements preventing false

\footnotetext{
${ }^{26}$ The importance of not starting with the teaching of the dangers of nature has been emphasised by disaster educationalists such as Katada (2012). In tsunami education, he argues that teaching about the sea and its role has to come before talking about a tsunami.
}

rumours and mass panic and to co-habit with an active volcano. $^{27}$

\subsection{Agency and Knowledge as a Basis for Positive 'Outcome Expectancy'}

It can be considered that the development of agency and the control of emotion, which are the capacity of individuals, would have an impact on outcome expectancy - the individual-level factor in CET. A person with a proactive and responsible attitude is likely to be interested in learning about the volcano and volcanic hazards of the region. If the gained knowledge is balanced and correct, the person will probably build a belief that individual actions can influence her/his own safety. Individuals with such belief tend to show an intention to prepare themselves for disasters, as CET suggests. Conversely, a person who does not have a proactive and responsible attitude is less likely to be interested in learning about local environments and risks. Without the balanced and correct knowledge of the region, the person is apt to develop negative outcome expectancy believing that no individual actions can make difference to personal safety.

\subsection{Developing Preparedness Through Collaborative Projects}

One of the key means of promoting the importance of agency and the control of emotion in the case of SV is through collaborative projects. The Centenary Project was planned and delivered by a committee comprising the Kagoshima

\footnotetext{
${ }^{27}$ Fostering both the balanced and the correct knowledge is implemented in for example, 'Sakurajima and Us [Sakurajima to watashitachi]', a textbook which was created by a group of researchers at Kagoshima University (2014) for the purpose of disaster education offered at schools in Kagoshima Prefecture. The textbook comprises first, 'Our Sakurajima' in which the beauty of the nature and the benefits that the volcano brings are described, and then 'Knowing Sakurajima and its eruptions' which explains the mechanism and the impact of eruptions.
} 
prefectural and municipal governments, academic experts, museums and libraries, the national and municipal meteorological agencies, the development bureau, the chamber of commerce, the confederation of tourism, neighbourhood associations and the media (Centenary Committee 2014, p. 161). The project included a number of sub-programmes aiming to convey the lessons learned from the volcanic disaster for future generations, and also to raise the awareness of volcanic preparedness amongst citizens. ${ }^{28}$ Those programmes can be identified as kyojo projects based on collaboration amongst a wide range of stakeholders. 'Kyojo', which literary means 'helping each other', is a policy term widely used in Japan in the area of disaster management and preparedness. 'Kyojo' stresses the population's commitment and cooperation which has to be mobilised in preventing and mitigating foreseen large-scale disasters (Murosaki 2013).

Kagoshima's kyojo programmes were designed to attract a wide audience outside as well as inside the prefecture in the form of informal learning. The programmes ranged from an exhibition of the sketches and the photographs of the Taisho Eruption, to a 160-page documentation of the knowledge and experience of Sakurajima to date. Two programmes are briefly described here as an illustration of the teaching and learning of 'do not rely on authorities' and 'be frightened effectively'. The first programme is 'Creating a stone-rubbing of the Sakurajima Eruption Monument', which aimed to promote an understanding of the inscription discussed earlier through a stone-rubbing of 'The Monument to the Distrust of Science'. One of the participants commented, 'I hadn't known much

\footnotetext{
${ }^{28}$ With the slogan, 'Let's rethink the potential of the volcano! Let's benefit from SV!', the project included the following sub-programmes: 'Rethinking SV', 'Benefiting from SV' and 'Conveying the lessons learnt'. The International Association of Volcanology and Chemistry of the Earth's Interior (IAVCEI) Conference 2013Learning from the world, was also one of the sub-programmes. The IAVCEI was an opportunity for volcanologists from different parts of the world to meet in Kagoshima to share and discuss the findings from cutting-edge research.
}

about Sakurajima before. Through the stone-rubbing, I have learned about the sad story of the mistake made by the local meteorological agency.... I want to participate in more activities and know more about Sakurajima' (Kagoshima City 2013). 'A stamp rally visiting nine places in Sakurajima' combined tourism with education, including a visit to the 'buried' shrine gate in the Kurokami district. ${ }^{29}$ The chairman of the community association [chonaikai] explained, 'the community members are looking after this buried shrine gate for the memory of the Taisho Eruption. We hope to raise awareness of volcanic preparedness' (Kagoshima City 2013).

The Centenary Project ended in March 2014, leaving a legacy of kyojo projects. For example, a not-for-profit organisation and academics collaborated to set up the Sakurajima Museum, based on the idea of 'ecomuseum' (Fukushima and Ishihara 2004), defining the whole island of Sakurajima as a museum. The museum undertakes research and develops the teaching and learning of the history and ecology of the island. Similarly, Geo Park virtually puts Sakurajima and surrounding bays together and promotes 'the links between the volcano, the people and nature' (Geo Park Committee, n.y.). While promoting tourism, lifelong learning and disaster preparedness, both projects aim to contribute the community building and the economic development of the region. It is considered in Kagoshima that making the most of the benefits of the volcano as well as learning to be prepared effectively for volcanic hazards is the way to achieve 'kyozon'-living with the volcano.

\subsection{Kyojo Encompassing 'Community Participation' and 'Collective Efficacy'}

Linking kyojo with the community-level factors of CET, this paper suggests that 'kyojo' is a notion that encompasses both community participation and collective efficacy. At the community

\footnotetext{
${ }^{29}$ Two-third of the three-metre shrine gate was covered with ash fall and lava from the Taisho Eruption.
} 
level, participation was fundamental in the Centenary Project. The events were developed by diverse members of the region and participated by wider communities, aiming to raise awareness and build the knowledge-base of the general public. Through community participation, people were involved in the teaching and learning about the Taisho Eruption and volcanic preparedness. Kyojo thus is about community participation. Kyojo is also about collective efficacy. As identified in the comparative study by Paton et al. (2013, p. 29) that examined Kagoshima residents' preparedness intentions, 'the high frequency of experience of volcanic hazards in Kagoshima increases its citizens' familiarity with the hazards and what works to manage their risk' (Paton et al. 2013 , p. 29), which has resulted in the community's developing 'building codes, ash removal practices and community attitudes and preparedness to facilitate continuity of societal functions during periodic volcanic episodes'. Based on the assessment of 'what works to manage their risk', this community has planned 'practices' and 'preparedness'. It is suggested that the notion of 'kyojo' includes such assessment and decision-making phase, which is identified as collective efficacy in CET.

\subsection{Kyojo as a Contributor to 'Empowerment' and 'Trust'}

The relationship between kyojo and the societal-level factors - empowerment and trustcan be considered as the following. The more kyojo programmes - the programmes created on the basis of collaborative partnerships amongst a wide range of stakeholders - are developed and delivered, the more empowering and trustworthy relationships between community members and authorities would be built. Through collaborative working, both parties get to know each other, exchange ideas and information and co-construct preparedness schemes. The significant point in the case of SV is that after the Taisho Eruption in which the islanders who lost their lives following the village mayor's instruction, trust in the authorities must have decreased. As Paton et al. (2013, p. 22) indicate, 'people's perception of the quality of their (historical) relationship with a source of information influences their interpretation of the value of information in a way that is independent of the information itself'. The two major lessons 'do not rely on authorities' and 'be frightened effectively' have played a pivotal role in the rebuilding of trust in the authority. Today, Kagoshima citizens have become familiar with the hazards and how to cope with them. The high frequency of volcanic hazards has meant the information provided by official agencies to guide their preparing has been critical. This was anecdotally confirmed a number of times while the empirical fieldwork was undertaken in Kagoshima. It would be fair to say that the trust relationship between citizens and the authorities in the Kagoshima region has been rebuilt since the Taisho Eruption. The suggestion here is that the kyojo approach has contributed to the building of the empowering and trustworthy relationship.

The SV case appears to have a relatively high degree of individual, community and societal engagement in preparedness, although this hypothesis requires testing. The challenge in the region is, however, their preparedness also has to take into consideration an infrequent mega-scale eruption, which requires evacuation from the island before the eruption starts. This is the topic of the next section.

\section{The Challenge of Living Under the Level 3 Warning}

As a result of the volcanic warning Level 3 being kept unchanged since April 2012, 'Level 3' has become a norm in Kagoshima Prefecture. Being familiar with small-scale eruptions and ash fall, the local population are capable of facilitating 'continuity of societal functions during periodic volcanic episodes' (Paton et al. 2013, p. 29), not markedly changing their daily routines. Such circumstances could lead to 'the normalcy bias', 
which was introduced by Omer and Alon (1994, p. 273). ${ }^{30}$ Defined as 'underestimating the probability or extent of expected disruption', the term 'the normalcy bias' refers to the perception of the authorities during the crisis that 'it cannot happen to us' or 'life will be unchanged, even after a disaster', resulting in failing to plan for disaster, let alone involving the public in planning for disaster (Valentine and Smith 2002, p. 186). The researchers also identified the so-called 'abnormalcy bias', which refers to the authorities' 'underestimating victims' ability to cope with disaster' (Omer and Alon 1994, p. 273) with a view that 'the people cannot handle a threat of impending disaster' ending up in either panic, shock or looting (Valentine and Smith 2002, p. 186).

As indicated by the curator and researcher of the prefectural museum (Interview 2014), in the case of Kagoshima, 'the normalcy bias' appears to reside more in the public rather than the authorities. Although further investigation is required to confirm this claim, the point to be made here is that 'living with an active volcano' seems to promote the normalisation of 'the state of alert', and under such circumstances, there is a risk of people becoming less interested in preparing themselves for a more severe disaster. In other words, Kagoshima residents have high familiarity with preparedness for Level 3 and small-scale volcanic hazards, but that does not necessarily mean they are equally prepared for an eruption of the scale of the Taisho disaster.

\section{Conclusion}

The teaching and learning of and for volcanic hazards, as well as volcanology and seismology have dramatically advanced since SV's Taisho Eruption of 1914. Applying the individual/ community/societal framework of CET, this paper has discussed a model for 'living with an active volcano', with a focus on how the lessons

\footnotetext{
${ }^{30}$ Their research was in the context of the Gulf War to refer to the response of the authorities to the threat of attacks.
}

learned from previous experiences have been utilised in present-day preparedness programmes in the Kagoshima region. The overall argument has been that the SV case can be identified as 'the integrated model' endorsed by CET, largely because of their kyojo practices represented in the Centenary Project and the Sakurajima Museum, which incorporated 'disaster management' and 'community development' through 'mobilising community resources to facilitate adaptive capacity rather than having institutional decisions imposed upon a community' (Paton 2008 , p. 29). The integrated model entails 'natural coping mechanisms' (Paton 2008, p. 29), or in Yamori's (2012) term, 'everyday preparedness [seikatsu bosai]'. In developing such 'built-in' (Yamori 2010) mechanisms, kyojo becomes critical. This conclusion has been drawn from a qualitative examination of the findings of the SV case against the five factors of CET.

Firstly, at the individual level, the paper has suggested that two principles identified in the SV case form the basis for positive 'outcome expectancy'. One principle is an emphasis on developing agency so that individual citizens develop ownership in making decisions about their behaviour in emergency situations. This has been expressed by a local lore, 'do not rely on authorities'. The other is an emphasis on gaining the balanced and correct knowledge of the volcano and volcanic hazards. The knowledge allows one to 'be frightened effectively' as other local lore advocates, and also prevents one from being distracted by false information. Positive outcome expectancy is likely to develop in a person who has a proactive and responsible attitude to gain the balanced and correct knowledge.

In terms of the community and societal levels, the paper has demonstrated that 'kyojo'-collaborative partnerships-plays a significant role. It is suggested that kyojo encompasses both of the community-level factors-'community participation' and 'collective efficacy'. Participation is a prerequisite for kyojo activities. The efficacy of the community to make collective judgements and reach decisions is likely to be developed through collaboration and exchanging of ideas 
and information. It is also suggested that kyojo is an approach that contributes to the building of societal-level 'empowerment' and 'trust' between community members and authorities.

The above analysis requires strengthening by further researching the relationships between agency, knowledge and kyojo, and outcome expectancy, community participation, collective efficacy, empowerment and trust. Moreover, clarifying the role of agency, knowledge and kyojo in linking 'disaster management' with 'community development' and vice versa is needed in presenting a concrete picture of how 'an integrated model' might look like.

This final part of the paper addresses a specific kind of challenge that the population in the Kagoshima region seems to be facing in living under the continuous Level 3 condition. Even if the population has a high level of preparedness for frequent volcanic hazards, whether the same applies to Taisho-Eruption-scale hazards remains questionable. Having developed individual agency, community participation and trust between citizens and authorities, the population may be immune to 'the abnormalcy bias'; however, a possibility of them growing 'the normalcy bias' appears to be an emerging concern.

Acknowledgments This paper was developed on the basis of the findings from the research project, Critical Infrastructure Failure and Mass Population Response, funded by the Economic and Social Research Council in the UK. I would like to thank all of the interviewees for providing me with important information, and Taichi Kaneshiro of MEXT for his co-operation in arranging the interviews.

Open Access This chapter is distributed under the terms of the Creative Commons Attribution-NonCommercial 4.0 License (http://creativecommons.org/licenses/by-nc/4.0/), which permits any noncommercial use, duplication, adaptation, distribution, and reproduction in any medium or format, as long as you give appropriate credit to the original author(s) and the source, a link is provided to the Creative Commons license, and any changes made are indicated. The images or other third party material in this chapter are included in the work's Creative Commons license, unless indicated otherwise in the credit line; if such material is not included in the work's Creative Commons license and the respective action is not permitted by statutory regulation, users will need to obtain permission from the license holder to duplicate, adapt, or reproduce the material.

\section{References}

Ishihara K (2012) Understanding of volcanic phenomena and prediction of volcanic eruptions. Annuals Disaster Prevention Res Inst Kyoto Univ 55A:107-115

BBC News (2014) Japan volcano: 16 still missing after Mount Ontake eruption. http://www.bbc.co.uk/news/ world-asia-29472384. Accessed 6 Oct 2014

Cabinet Office (2011) Disaster management in Japan. Cabinet Office, Government of Japan, Tokyo

Central Disaster Council, Cabinet Office (2011) Learning from the history of disasters: volcanos [saigaishi ni manabu: kazan hen]. In: Expert Committee on Disaster Lessons. Cabinet Office, Government of Japan, Tokyo

Department of Domestic Science Education, Faculty of Education, Kagoshima University (2014) Sakurajima and us [sakurahjima to watashitachi]. Sakurajima Volcano Education Supplementary Reading Material, Department of Domestic Science Education, Faculty of Education, Kagoshima University, Kagoshima

Fukushima D, Ishihara K (2004) Practical research on educational dissemination for volcanic disaster prevention: a case study based on the Ecomuseum concept. Annuals Disaster Prevention Res Inst Kyoto Univ 47C, n. p

Geo Park Committee (n.y.) The vision of the Geo Park. http://www.kagoshima-yokanavi.jp/shizen/geopark/ geo05.html. Accessed 21 Oct 2014

Japan Meteorological Agency (2014). Sakurajima. http:// www.data.jma.go.jp/svd/vois/data/fukuoka/eng/506/ 506-eng.htm. Accessed 21 Oct 2014

Kagoshima City (2013). Sakurajima Taisho Eruption Centenary Project [Sakurajima taisho funka 100 shunen kinen jigyo]. Kagoshima Citizens' Common, 553

Katada T (2012) Disaster information and disaster education [saigai joho to bosai kyoiku]. The record of memorial symposium, 14th conference of the Japan Society Of Disaster Information. 28 Oct 2012

Kitagawa K (2014) Continuity and change in disaster education in Japan. Hist Educ. doi:10.1080/ 0046760X.2014.979255

Murosaki M (2013) The current situation of disaster projection, volunteering and kyojo, and future expectations [bosai to borantia to kyojo no genjo, soshite kongo eno kitai]', Keynote Lecture, Disaster Projection by All in Kobe-Expanding the Network of Kyojo Meeting, organised by the Cabinet Office, 27 Jan 2013. http://www.bosai-vol.go.jp/kyojo/murosaki. pdf. Accessed 21 Oct 2014

Omer H, Alon N (1994) The continuity principle: a unified approach to disaster and trauma. Am J Community Psychol 22(2):273-286

Paton D (2008) Community resilience: integrating individual, community and societal perspectives. In: Gow K, Paton D (eds) The phoenix of natural disasters: community resilience. Nova Science Publishers, New York, pp 13-31 
Paton D, Okada N, Sagala S (2013) Understanding preparedness for natural hazards: a cross cultural comparison. J Integr Disaster Risk Manage 3:18-35

Paton D, Jang L (2013) Increasing community potential to manage earthquake impacts: the role of social and cultural factors. In: Konstantinou KI (ed) Earthquakes: triggers, environmental impact and potential hazards. Nova Publishers, New York, pp 299-320

Paton D, Johnston D (2006) Disaster resilience: an integrated approach. Charles C. Thomas, Springfield

Preston J, Chadderton C, Kitagawa K (2014) The 'state of exception' and disaster education: a multi-level conceptual framework with implications for social justice'. Globalisation Soc Educ 12(4):437-456

Sakurajima Taisho Eruption Centenary Project Planning Committee (2014) The centenary memorial magazine of Sakurajima Taisho Eruption [taisho funka 100 shuunen kinenshi]. Sakurajima Taisho Eruption Centenary Project Planning Committee, Kagoshima

Shiroshita H (2010) Towards the actualisation of collaborative learning for disaster prevention [bosaikyoiku no jitsugen ni mukete]. In: Safety science for disaster prevention and reduction - a proposal in building a safe and secure society [bosai/gensai no tameno shakaianzengaku — anzen/anshin na shakai no kochiku eno teigen]. Faculty of Safety Science, Kansai University ed., Mineruva Shobo, Kyoto, pp 98-114
Suzuki T (2014) The present situation and assignment of monuments for Mt. Sakurajima Eruption in Taisho 3 (1914) 2. Res Rep Kagoshima Prefectural Mus 33:71-88

Takahashi K (2007) Risk management on volcanic disaster. J Saf Issues, Japan Society of Civil Engineering 2:17-22

The Expert Committee to Discuss Disaster Education and Management Considering the Lessons Learnt From the Great East Japan Earthquake [Higashinihon daishinsai o uketa bosaikyoiku/bosaikanri ni kansuru yushikisha kaigi] (2012) The Expert Committee to discuss disaster education and management considering the lessons learnt from the great East Japan Earthquake-final report [Higashinihon daishinsai o uketa bosaikyoiku/ bosaikanri ni kansuru yushikisha kaigi-saishu hokoku]'. http://www.mext.go.jp/b_menu/shingi/chousa/ sports/012/toushin/1324017.htm. Accessed 22

Valentine PV, Smith TE (2002) Finding something to do: the disaster continuity care model. Brief Treat Crisis Interv 2(2):183-196

Yamori K (2010) The current state and prospects of disaster education - 15 years since the Hanshin/Awaji Earthquake. J Jpn Nat Disaster Sci 29(3):291-302

Yamori K (2012) The great East Japan Earthquake and 'everyday preparedness' [higashinihondaishinsai to "seikatsu bosai"]. Build Maintenance Manage Cent, J Re 175:n. p 